\title{
The Perspectives of Medical Students in China to Undergo Short-Term Training Abroad
}

\author{
Yu-zhuang Huang ${ }^{1}$, Xin Cheng ${ }^{2}$, Beate Brand-Saberi ${ }^{3} \&$ Xuesong Yang ${ }^{2}$ \\ 1 office of International Exchange and Cooperation,Jinan University, Guangzhou 510632,China \\ ${ }^{2}$ Medical School, Jinan University, Guangzhou 510632, China \\ ${ }^{3}$ Department of Anatomy and Molecular Embryology, Ruhr-University Bochum, Bochum, Germany \\ Correspondence: Xuesong Yang, Medical School, Jinan University, Guangzhou 510632, China.
}

Received: June 27, 2018

doi:10.5430/ijhe.v7n4p203
Accepted: August 19, 2018

Online Published: August 22, 2018

URL: https://doi.org/10.5430/ijhe.v7n4p203

\begin{abstract}
Jinan University in Guangdong province has several years experience of sending medical students abroad for short-term training, based on the schools' agreement with international universities. Currently, we analyze the problems and experience including the medical students' favorite countries, timing, purposes, academic marks, and expenses etc., which came forth from medical students of Jinan University who had participated in the short-term training in the past several years. Our survey suggests that the choices of Chinese medical students about the host universities vary, although the universities in Western countries are still the most popular. The optimal timing the students prefer for short-term training abroad is during vacation especially after grade 2 . Broadening the horizons, learning the different knowledge and increasing their academic experience are the major objectives for most exchange students. Furthermore, the survey shows that students hope to improve exchange students' status management and credit acknowledgement system among interschool administrations. This study could supply useful information for the upcoming exchange students for Chinese medical universities/schools and meanwhile, for the host universities receiving Chinese medical students in the world. Hence, both universities and medical students will benefit for more efficiently implementing the exchange programs in the future.
\end{abstract}

Keywords: medical students, short-term study abroad, exchange program

\section{Introduction}

Most of medical student exchange programs in all countries have been implemented in coordination with The International Federation of Medical Students' Associations (Bencevic, H. \& A. Babic, 2001). The current Chinese medical education system for Western medicine physicians is established in Chinese medical schools based on evidence-based medicine (Greig, J.D., 1994), which has been developed in Western centuries over centuries. Although there are quick and robust achievements in the field of medical education and research in China, the current status on medical education is still not satisfying in international comparison. In particular, the progress of teaching theories is lagging behind the ones of the top medical schools in the world (Sheng, Y., 1996). Moreover, the fast development of life sciences in the last few decades has dramatically enriched medical knowledge and also pushed the reform of medical education worldwide forward. However, the Chinese medical education system has generally kept unchanged until now, which is partially because it is a tremendous task if the medical education system is changed throughout China.

Many medical schools recognize the increasing importance of global health training. International health training are a popular component of many medical schools and residency program curricula, and are reported to have positive educational influences on participants' knowledge, skills, and attitudes (Thompson, M.J., et al., 2003). A 2009 survey found that approximately $25 \%$ of U.S. medical students graduated with some type of international medical experience (Drain, P.K., et al., 2009). Therefore, in this case, it is certainly beneficial for Chinese medical students to participate in some international exchange programs if conditions are allowing.

The medical students at Jinan University Medical School study clinical medicine for either 5 or 6 years at school. The difference of school years is due to the different sources of medical students. They will study one year more at school if the students come from outside of China Mainland since they need extra time to overcome the linguistic and cultural barrier. Generally, as the other medical schools in the world, the program of clinical medicine at Jinan 
University provides sound basic medical theory, expertise and clinical skills in modern medicine. The curriculum consists of a pre-clinical and a clinical period during which a limited number of medical students are given the opportunity to spend short term clerkships at foreign medical schools. The outgoing students at Jinan University Medical School are selected on the first-come-first-severed basis, and the clerkships are approved by pending available vacant slots in the chosen time. Here, we call those outgoing students "exchange students", since medical students from Jinan University and signatory foreign universities should come to other universities based on bilateral agreements. However, the majority of the exchange students have been the medical students from Jinan University Medical School so far. Those medical students keep their school enrollment at Jinan University, and they have to return to Jinan University, to complete their entire study and obtain their degree after the abroad exchange programs.

In this way, the student exchange has been implemented already for many years at Jinan University. To further efficiently perform the program in the future, we carried out a study within the medical students at Jinan University who had participated in the exchange program. The purpose of this study is to summarize and assess the perspectives of students' exchange program, including their country preferences and the most suitable time for the exchange program etc. It is furthermore our hope to detect existing problems of this program, in order to avoid their reoccurrence in the future. Meanwhile, the pilot study information about the interest of outgoing Chinese medical students could be valuable for host universities or hospitals abroad as well.

\section{Material and Methods}

\subsection{Data Sources}

The data was collected from the medical students at Jinan University Medical School, who participated in short-term training aboard, in the form of questionnaires through QQ or WeChat. The items of the questionnaires are shown in Table 1, and the topics of the questions were chosen on the basis of obvious interesting points among outgoing medical students. QQ is an instant-messaging software that has been currently used mainly in Mainland of China. WeChat is a Chinese multi-purpose messaging, social media and mobile payment app developed by Tencent, according to Wikipedia. Simply because both of them are very popular among Chinese students, we employed them to collect the data from the population of particular medical students at Jinan University Medical School. The survey was conducted by Ms. Yu-zhuang Huang, who is responsible for organizing the students exchange program at Jinan University Medical School. Therefore, she could efficiently implement the survey and obtain the feedback from the medical students. Totally, 300 answers were received from the issued 400 questionnaires from the outgoing medical students after they returned to Jinan University. 100 students were excluded due to non-response. Therefore, data from 300 students were included in the final analysis.

Table 1. Items of the survey

\section{Items}

1. I think the optimal timing for short-term training abroad is

2. I think the suitable duration for exchange program is

3. I think the optimal destinations for short-term training abroad is

4. My anticipation for the interschool exchange program are

5. My expectations of the cost on the exchange program is

6. For me, the ideal pattern of exchange program is

7. My comments about the university administration on exchange programs are

8. My suggestions about the exchange program are (free response) 


\section{Results and discussion}

\subsection{The Optimal Timing for Short-Term Training Abroad}

As mentioned in Introduction, medical students from Jinan University Medical School involved in the exchange programs will obtain their degrees at Jinan University. In other words, those activities of exchange abroad should not dramatically interfere with their normal study at Jinan University Medical School. Hence, we firstly designed a survey about what is the optimal time for training abroad among the medical students who were interested in going abroad. The survey showed that over half of the students preferred to utilize their summer (July to August) or winter (January to February) vacation to go abroad (Fig. 1), which obviously indicates that they did not miss too many lectures at Jinan University when they came back. Medical school can be a tough experience globally. There are very heavy learning tasks for medical students in the curriculum of Jinan University Medical School, therefore, they would have to postpone their graduation if they could not get enough compulsory credits because of going abroad.

Concerning which academic year is a good timing for going abroad, $16 \%$ of the interviewed students considered it to be either after year 2 or later, while $10 \%$ of the interviewed students preferred to go after year 1 (Fig. 1). This probably suggests that they would like to master more medical knowledge at home before going abroad, so that they first collect more credit points than going early. After all, the year 2-medical students have had a much clearer idea about medicine in comparison to freshmen, so that they felt more confident to communicate with the teachers and students abroad. In addition, the chance of going abroad might lay a foundation for their future career development as well.

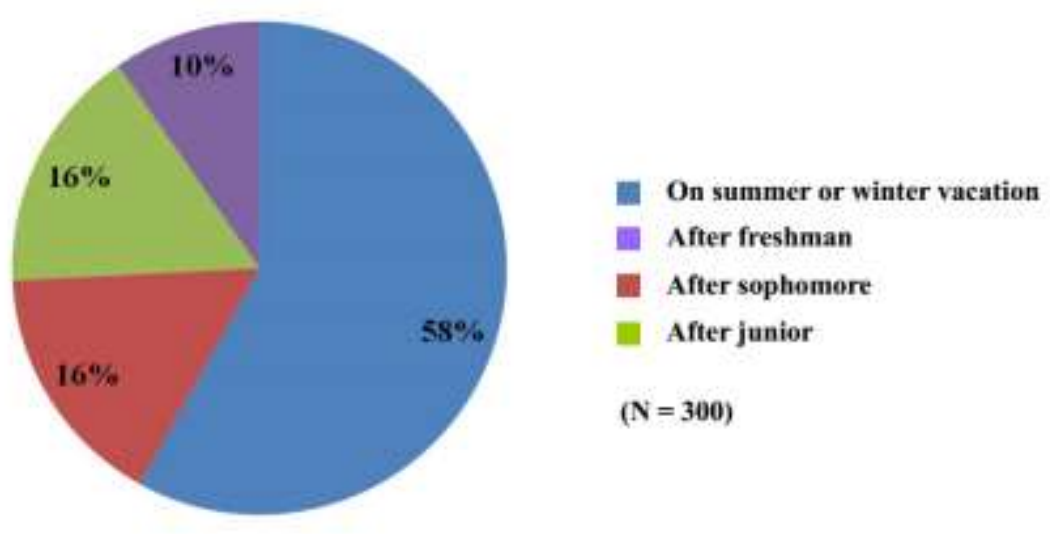

Figure 1. Medical students' preferences for the timing of the interschool exchange

The pie chart shows the percentages of the 300 interviewed students' favorite timing to go abroad.

Another issue about the timing is regarding the optimal duration of their stay abroad. From the survey results, we can see that $39 \%$ of the interviewed students preferred to stay longer than two vacations (summer or winter vacation), especially $29 \%$ liked to stay for one academic year. Both of the percentages are higher than the ones who want to stay aboard for one semester (13\%) and only one vacation (19\%) (Fig. 2). This suggests that they hope to stay abroad longer in order to have plenty of time to communicate with local teachers and students, as well as knowing the "secondary" campus more sufficiently. For the exchange students, a conflict arises regularly between their wishes to study abroad for a longer time and the avoidance of missing lectures at home. Hence, they need to find the equilibrium point between both. 


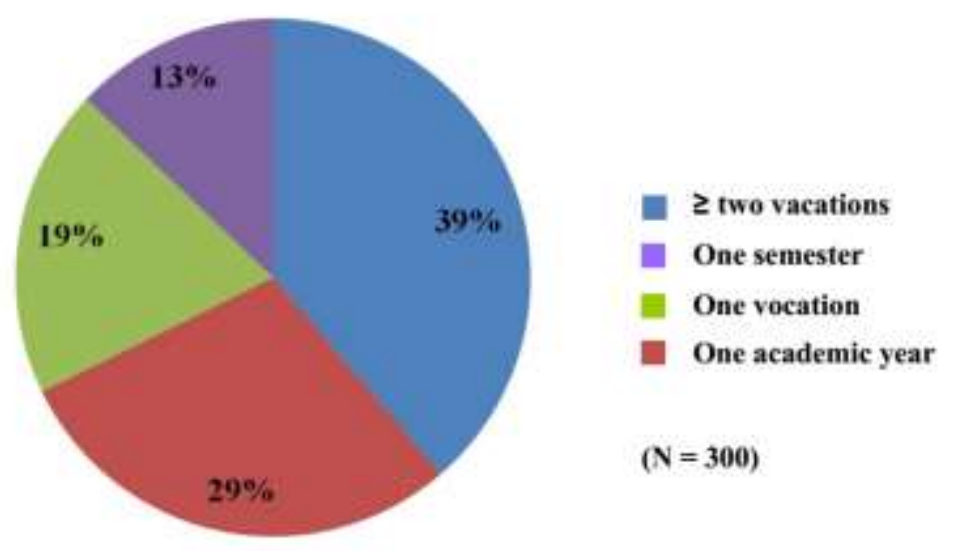

Figure 2. Preferred duration of the interschool exchange

The pie chart shows the percentages of the 300 interviewed students' favorites about the duration of the exchange.

\subsection{The Optimal Destinations for Short-Term Training Abroad}

In order to simplify our questionnaire, we divide the locations of exchange program into two parts: Western countries (Europe and America etc.) and HongKong/Macau/Taiwan/Southeast Asia. Meanwhile, we added domestic exchange destinations including the universities within Guangdong province and outside Guangdong province as internal reference. The survey revealed that majority $(65 \%)$ of students like to go to Western countries, which is much higher than the percentage of students who like to go to HongKong/Macau/Taiwan/Southeast Asia (13\%). This number is even lower than those choosing the famous universities outside Guangdong province (19\%), and the least percentage is to the universities within Guangdong province (Fig. 3). There are plenty of reasons for the favourite destination of exchange students' choices. The European and American universities were the first choice because mainly Western medicine was born in Europe (Rolleston, H., 1939) and developed very well in the European and American area, as well as the advanced science and technology policy contributed to a well developed economy in many Western countries. Therefore, it is undoubtedly beneficial to the future of exchange students to be partly trained there. The reason that a high proportion of students $(19 \%)$ chose to exchange to the famous Chinese mainland medical schools outside Guangdong province is because the majority of the interviewed students are from the Traditional Chinese Medicine program. They consider that the mainland China is the headstream of Traditional Chinese Medicine (Zhang, R.W., 2017), as well as the site of authorities in the field of Traditional Chinese Medicine. Therefore, the first choice of the majority of Traditional Chinese Medical students is to participate in the exchange program sponsored by the famous Chinese universities in the mainland of China. Some of the exchange students (13\%) chose to go to HongKong/Macau/Taiwan/Southeast Asia because of the similarities in culture compared with the mainland of China, as well as the high standard of science/technology and the same language in some regions. One more reason is that the living expenses in HongKong/Macau/Taiwan/Southeast Asia are generally lower than in Europe and America. In sum, not only European and American universities but also famous universities in Asia and even within the mainland of China could be our partners for short-term exchange programs of medical students. In other words, many famous universities in the world could be acceptable for the exchange medical students. 


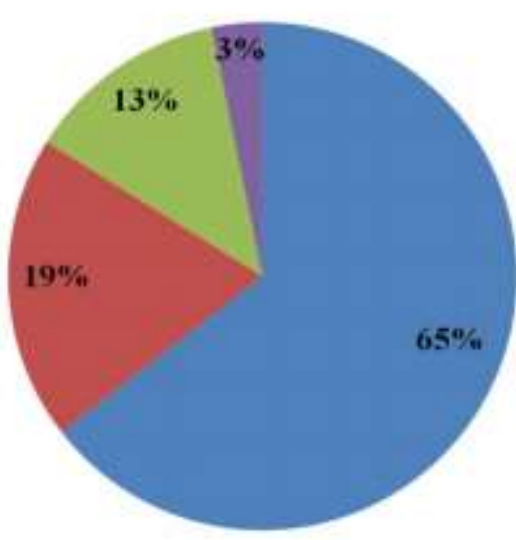

Medical Schools in

Western countries

Guangdong province

Hongkong/Macau/Taiwan and Southeast Asia

Domestic ones except for Guangdong

Figure 3. The medical students' preferences regarding the destinations of the interschool exchange

The pie chart shows the percentages of the 300 interviewed students' favorite destinations for interschool exchange.

\subsection{The Students' Objectives of Short-Term Training Abroad}

The survey about the students' expectations for the interschool exchange showed that $29 \%$ students expect to expand their knowledge; $25 \%$ students like to make new friends around the world and establish their own network; and more than $20 \%$ students yearn for exploring their secondary campus $(23 \%)$ or reinforce expertise learning (21\%) through the exchange programs (Fig. 4). First of all, the survey results indicate that widening their horizon, broadening their knowledge and increasing their academic experience are the major objectives for most of our exchange students. Meanwhile, making friends and establishing social networks on the secondary campus is also mentioned as a motivation to go abroad by the exchange students. Thus, we can see that the exchange students have an unambiguously positive perception of our interschool exchange program. It is actually in high accordance with the perception of our university on this issue. Medical education is not only a natural scientific discipline, but also comprises humanitarian aspects (Parent, K., et al., 2016) (Johna, S. \& S. Rahman, 2011). Exchange programs are considered to be an effective practice that strengthens students' professional skills, in which students have the opportunity to observe how the medical education is implemented elsewhere, and experience the different health systems.

Additionally, it was reported that having international health training experiences contributed to a more well-rounded training for medical students; students reported being more culturally competent and were more likely to choose a primary care specialty and/or a public service career (Jeffrey, J., et al., 2011). Our survey also suggested the exchange experience could continue to positively impact their awareness of cultural and socioeconomic factors and clinical and language skills, as mentioned in the open items of the questionnaire. The experience with different medical systems can help them gain better cultural understanding of medical care. Nonetheless, the affects at participants' perception of their future career choices needs more evidence to confirm in our program. 


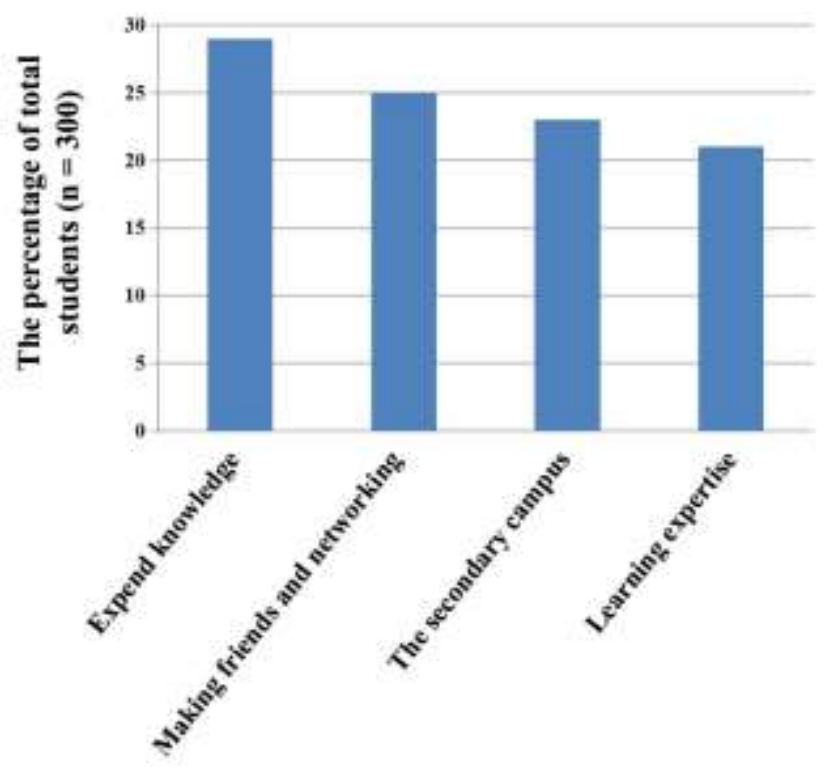

Figure 4. The medical students' purposes for the interschool exchange

The bar chart shows the percentages of the 300 interviewed students' purposes for interschool exchange. The students could have more than one option.

\subsection{The Students' Expectations Regarding University Administration Related to the Short-Term Training Abroad}

To investigate what is required for improving the exchange program, we inquired the expectations of the exchange students regarding university administration. 55\% exchange students hope that Jinan University acknowledges and transfers their credits obtained abroad, even credits not related to the college majors at Jinan University. 10\% exchange students expect that Jinan University records the credits obtained abroad for the different major curriculums. 35\% exchange students wish that Jinan University sets the same curriculum standard as the host universities, so that their credits earned abroad can be counted into their total credits at Jinan University (Fig. 5). The survey displays that the majority of exchange students dramatically valued the credit transfer between the two universities. If the university acknowledges the credits that they obtained abroad, the intentions of studying abroad of medical students can be expected to increase tremendously, because it would relieve the key worries of having to extend their studies to earn enough credits for the graduation at Jinan University. Definitely, students will obviously benefit more from the exchange if they could take advantage of the credits that they obtained abroad.
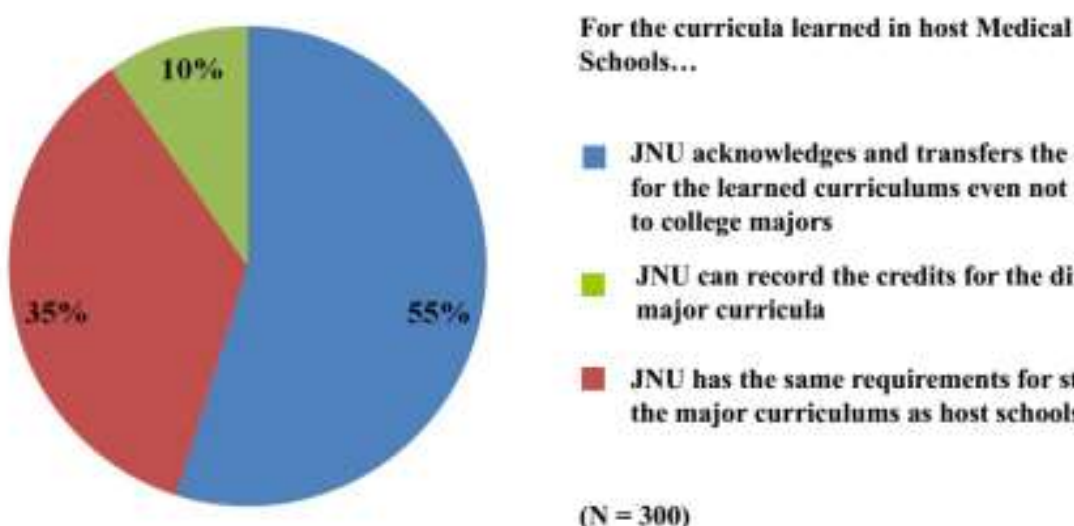

JNU acknowledges and transfers the credits for the learned curriculums even not relative to college majors

JNU can record the credits for the different major curricula

JNU has the same requirements for studying the major curriculums as host schools

$(\mathrm{N}=\mathbf{3 0 0})$

Figure 5. Medical students' expectations regarding the academic credit transfer during the interschool exchanges The pie chart shows the percentages of the 300 interviewed students' expectations regarding the university administration on academic credit transfer for interschool exchange.

We further investigated the medical students' thoughts regarding the expenses during the interschool exchanges. The 
survey showed that $42 \%$ exchange students hoped that the tuition fee can be waived and that they might get some allowances towards the living expenses from either of the universities, since exchange overseas is usually costly. $35 \%$ students think that it is fine for them to afford living expense as long as the tuition fee is waived. $13 \%$ exchange students consider it to be acceptable for them to afford their living expenses if half of the tuition fee is reduced, and $10 \%$ students even declared to be able to fully afford the tuition fee and living expenses (Fig. 6). Realistically, one of the most important issues related to the exchange programs is the economic problem that exchange students have to consider when studying abroad. It is because the total costs are generally much higher abroad than on campus of Jinan University. It presents a particular problem if the students are charged by extra-tuition fees in some host universities. Not many Chinese parents can afford the full extra tuition fees and living expenses, so that it is reasonable that nearly half exchange students wish to waive the tuition fee and have allowances for the living expenses simultaneously. At least, they hope that the tuition fees could be waived, indicating the cost of studying abroad is the issue that they have to prudently consider. Just because of this, both of the exchanging universities administrations should consider to reduce the cost of exchange students using any means if possible, such as waiving the tuition fee, supplying living expenses or travel reimbursement etc. It would be ideal if there were some founding opportunities available at university level, to financially support the global training of the exchange students.
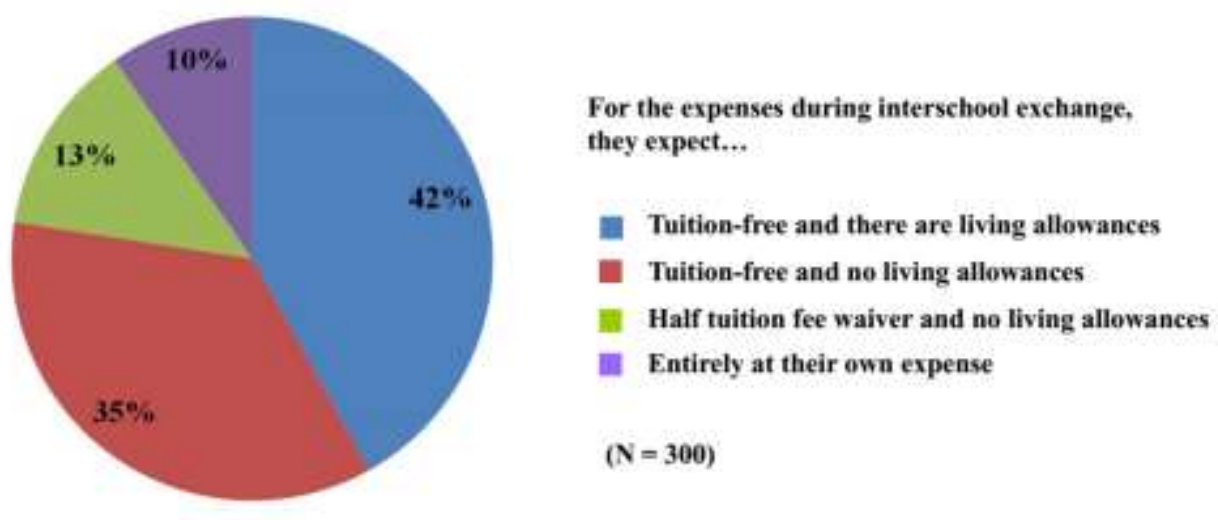

Figure 6. Medical students' thoughts about the expenses during the interschool exchanges

The pie chart shows the percentages of the 300 interviewed students' expectations to university administration on living expense support and scholarships for interschool exchange.

\section{Conclusions}

There has recently been an unstoppable trend on the internationalization of the medical education in China (Madani, M., et al., 2017). A survey about the possible problems during the exchange of medical students in the situation of internationalization was carried out at Jinan University. The results indicate that the choices of students about the host universities vary although the universities in Western countries are still the most popular. The diversity of choices derives from multiple factors such as the university ranking, economic development, living expenses, and their majors etc. Furthermore, the survey shows that students hope to improve exchange students' status management and credit acknowledgement system among interschool administrations. The improvement of performance management measures would certainly promote and refine the exchange programs.

\section{Limitations}

In this study, we did not limit our partner universities to the Western countries or the Asian countries because the students' choices were widely scattered. Furthermore, we did not divide the exchange students into particular groups such as based on their demographic characteristics and academic qualifications. Lastly, this work is a relevant exploratory evaluation related to Jinan University, but not limited to Jinan University. However, comprehensive survey and robust statistics are further needed to provide more reference to the other universities.

\section{Acknowledgments}

This study was supported by the $17^{\text {th }}$ and $19^{\text {th }}$ research projects of pedagogical reform at Jinan University (JG2015071, JG2017088). 


\section{Conflict of interests}

The authors declare that there are no competing interests.

\section{References}

Bencevic, H. \& A. Babic. (2001). Medical students exchange program organized by Croatian Medical Students International Committee, 1996-2000. Croat Med J, 42(1), 83-7.

Drain, P.K., et al. (2009). Global health training and international clinical rotations during residency: current status, needs, and opportunities. Acad Med, 84(3), 320-5. https://doi.org/10.1097/ACM.0b013e3181b18078

Greig, J.D. (1994). The westernization of Chinese medicine and medical education. Hangzhou leads by example. Scott Med J, 39(4), 123-5. https://doi.org/10.1177/003693309403900410

Jeffrey, J., et al. (2011). Effects of international health electives on medical student learning and career choice: results of a systematic literature review. Fam Med, 43(1), 21-8.

Johna, S. \& S. Rahman. (2011). Humanity before Science: Narrative Medicine, Clinical Practice, and Medical Education. Perm J, 15(4), 92-4.

Madani, M., et al. (2017). Establishment of medical education upon internalization of virtue ethics: bridging the gap between theory and practice. J Med Ethics Hist Med, 10, 3.

Parent, K., et al. (2016). Teaching Patient- and Family-Centered Care: Integrating Shared Humanity into Medical $\begin{array}{llllll}\text { Education } & \text { Curricula. } & \text { AMA } & \mathrm{J} & \text { Ethics, } & 18(1),\end{array}$ https://doi.org/10.1001/journalofethics.2016.18.1.medu1-1601

Rolleston, H. (1939). The History of Clinical Medicine (Principally of Clinical Teaching) in the British Isles: (Section of History of Medicine and Clinical Section). Proc R Soc Med, 32(9), 1185-90.

Sheng, Y. (1996). [Sixty years of study on history of chinese medical education]. Zhonghua Yi Shi Za Zhi, 26(3), 170-8.

Thompson, M.J., et al. (2003). Educational effects of international health electives on U.S. and Canadian medical students and residents: a literature review. Acad Med, 78(3), 342-7. https://doi.org/10.1097/00001888-200303000-00023

Zhang, R.W. (2017). Traditional Chinese medicine: research and development, globalization, and regulation. Chin J Nat Med, 15(1), 1-3. https://doi.org/10.1016/S1875-5364(17)30002-X 